\title{
Peer Review of "Use of Smartphone Apps for Improving Physical Function Capacity in Cardiac Patient Rehabilitation: Systematic Review"
}

\section{Karla Goessler, $\mathrm{PhD}$}

Faculty of Medicine, University of Sao Paulo, Sao Paulo, Brazil

\section{Related Articles:}

Preprint: https://preprints.jmir.org/preprint/21906

Authors' Response to Peer-Review Reports: https://med.jmirx.org/2021/3/e33179/

Published Article: https://med.jmirx.org/2021/3/e21906/

(JMIRx Med 2021;2(3):e33181) doi: 10.2196/33181

\section{KEYWORDS}

cardiac rehabilitation; physical capacity; exercise; smartphone apps

This is a peer-review report submitted for the paper "Use of Smartphone Apps for Improving Physical Function Capacity in Cardiac Patient Rehabilitation: Systematic Review”.

\section{Review Round 1}

\section{General Comments}

This is a systematic review [1] investigating the utilization of smartphone apps for improving physical function capacity in cardiac rehabilitation (CR). Please find below my comments/suggestions.

\section{Specific Comments}

\section{Major Comments}

1. CR interventions seem to be quite different between studies, making future comparisons inappropriate (ie, for CR programs including exercise programs, I would expect improvements in cardiorespiratory fitness (CRF), while for programs including diet, this outcome might not change).

2. It is not clear how authors selected the papers. This process makes it difficult to understand the results, as the outcomes and types of interventions are quite different between studies. As the main outcome in CR is CRF, I would suggest making it your primary outcome for selection of the studies.

\section{Minor Comments}

\section{Methods/Results}

1. I would suggest including a PRISMA (Preferred Reporting Items for Systematic Reviews and Meta-Analyses) flow diagram for the study selection process. This is available at http://prisma-statement.org/prismastatement/flowdiagram.aspx.

2. Tables 2 and 3 are not clear.

\section{Conflicts of Interest}

None declared.

\section{Reference}

1. Tuttle K, Kelemen A, Liang Y. Use of smartphone apps for improving physical function capacity in cardiac patient rehabilitation: systematic review. JMIRx Med 2021 Sep 15;2(3):e21906 [FREE Full text] [doi: 10.2196/21906]

\author{
Abbreviations \\ CR: cardiac rehabilitation \\ CRF: cardiorespiratory fitness \\ PRISMA: Preferred Reporting Items for Systematic Reviews and Meta-Analyses
}


Edited by E Meinert; this is a non-peer-reviewed article. Submitted 26.08.21; accepted 26.08.21; published 17.09.21.

Please cite as:

Goessler $K$

Peer Review of "Use of Smartphone Apps for Improving Physical Function Capacity in Cardiac Patient Rehabilitation: Systematic Review"

JMIRx Med 2021;2(3):e33181

URL: https://med.jmirx.org/2021/3/e33181

doi: $10.2196 / 33181$

PMID:

(CKarla Goessler. Originally published in JMIRx Med (https://med.jmirx.org), 17.09.2021. This is an open-access article distributed under the terms of the Creative Commons Attribution License (https://creativecommons.org/licenses/by/4.0/), which permits unrestricted use, distribution, and reproduction in any medium, provided the original work, first published in JMIRx Med, is properly cited. The complete bibliographic information, a link to the original publication on https://med.jmirx.org/, as well as this copyright and license information must be included. 